
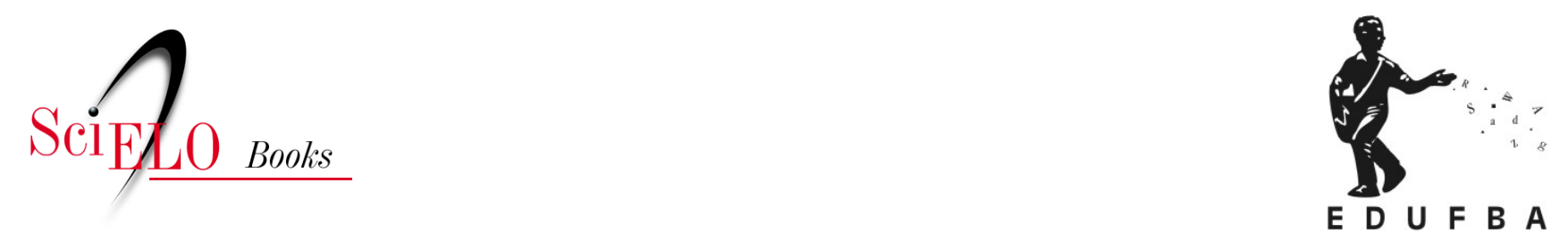

\title{
Capítulo 5 \\ A dialética do pertencimento versus solidão: travessias na fronteira simbólica do tornar-se mãe
}

\author{
Vívian Volkmer Pontes
}

\section{SciELO Books / SciELO Livros / SciELO Libros}

PONTES, V.V. A dialética do pertencimento versus solidão: travessias na fronteira simbólica do tornar-se mãe. In: Trajetórias interrompidas: perdas gestacionais, luto e reparação [online]. Salvador: EDUFBA, 2016, pp. 146-162. ISBN: 978-85-232-2009-9.

https://doi.org/10.7476/9788523220099.0007.

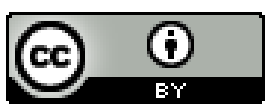

All the contents of this work, except where otherwise noted, is licensed under a Creative Commons Attribution 4.0 International license.

Todo o conteúdo deste trabalho, exceto quando houver ressalva, é publicado sob a licença Creative Commons Atribição $\underline{4.0}$. 
CAPÍTULO 5
A dialética do pertencimento versus
solidão: travessias na fronteira
simbólica do tornar-se mãe 


\section{Narrativa autobiográfica da trajetória reprodutiva de Juliana no contexto privado de saúde}

Todas as crianças nascendo e só

a minha morrendo. (Juliana)

Juliana tem 36 anos, trabalha como médica ginecologista em uma cidade do interior da Bahia, mas é natural de Salvador. Considera-se solteira e possui história reprodutiva marcada por três gestações e três abortos sucessivos e espontâneos, ocorridos no período de um pouco mais de um ano. Relata que "sempre quis ser mãe", que toda "mulher tem que ter filhos" e que não tê-los significa "ficar só na vida". A perspectiva de um futuro solitário, caso não se torne mãe, foi construída através dos diálogos e de histórias narradas e vividas por outras mulheres da sua família da geração anterior à sua: "Fui criada com essa ideia, mulher tem que ter filhos. Sem filhos, fica sozinha, sem motivação". Ter um filho, então, lhe daria "paz no coração", seria o "fim da solidão", "não existiria mais vazio". Porém, apesar da vivência da maternidade consistir em algo que há muito deseja, metas profissionais fizeram-na adiar este projeto, considerado como uma etapa "normal", sendo pessoal e socialmente esperado na vida de qualquer mulher:

Na verdade, eu sempre quis ser mãe, sempre, sempre, sempre. Mas, assim, eu sempre fui postergando pra depois, até por conta da minha profissão, 'né', eu primeiro quis me formar, depois de me formar eu quis fazer a especialização, depois eu queria estabilidade financeira, acho que as mulheres nos dias de hoje, a maioria vai postergando mesmo. 
Pra mim ser mãe era uma coisa normal, todo mundo... qual é a sequência normal da vida da pessoa? Formar, casar, ter filhos. Isso é o básico, normal. Então ser mãe pra mim naquela época era normal, eu tinha formado, tinha casado, só faltava o quê, ter filho, eu só estava esperando, como eu disse, assentar as coisas, ter uma estabilidade financeira melhor, mas na minha cabeça eu ia ser mãe, e ia viver uma vida normal igual a todo mundo. O que de fato não aconteceu.

A rede de significados tecida em torno do signo e do desejo de maternidade revela-se, porém, um pouco mais complexa. Afinal, Juliana possui uma relação conflituosa com o parceiro, sendo a não maternidade um dos pontos centrais desse conflito. Isto porque o parceiro tem filhos de outros relacionamentos, sendo que um deles, o mais novo, foi gerado durante uma fase em que estavam afastados. O nascimento dessa criança foi um marco na história desse casal, que desde então vivencia conflitos que levaram a separações temporárias e recomeços também pouco duradouros. Para Juliana, o fato de uma outra mulher ter "dado" um filho ao parceiro lhe garante vantagens em termos de valor social perante esse homem e a rede social próxima. Assim, a única solução vislumbrada por Juliana era a de ter um filho com esse homem e, então, recuperar o valor simbólico que considerava possuir antes do nascimento dessa criança.

$\mathrm{Na}$ medida em que Juliana só conseguia vislumbrar o futuro com a existência de um filho - sendo este último uma possível solução para os problemas conjugais -, alguns esforços foram empreendidos para esse fim, como se reaproximar do parceiro durante o período fértil na tentativa de engravidar. O que, de fato, aconteceu. Três gestações seguidas de três abortos espontâneos. A história das gestações e subsequentes perdas, ocorridas no primeiro trimestre da gestação, foram acompanhadas de uma gradativa ampliação da ansiedade e do sofrimento emocional de Juliana.

A notícia da primeira gestação consistiu em um motivo de grande alegria por parte de Juliana e de seus familiares:

Quando eu soube que eu tava grávida, felicidade, pra mim e pra minha familia, minha familia também sempre quis, minha mãe sempre quis ter netos... a gente sempre foi criado na minha familia pra poder parir, gerar, criar familia, de pre- 
ferência familia grande, com três, quatro filhos, então quando eu me vi grávida foi uma satisfação, uma alegria muito grande, eu ia realizar o sonho meu e de minha familia.

Algumas semanas depois, porém, teve um pequeno sangramento, o que levou Juliana a buscar a assistência da "sua" médica ginecologista em Salvador. Durante o exame do ultrassom, a médica constatou que a idade fetal não era compatível com o tamanho do feto, confirmando o diagnóstico de aborto espontâneo. A vivência do aborto, porém, não despertou muita preocupação por parte de Juliana, que, por ser ginecologista, considerou-o como um evento normal, passível de acontecer em uma primeira gestação: “o primeiro eu pensei assim: 'Ah, é uma coisa normal, um aborto só, todo mundo tem, principalmente depois de você usar a pilula durante um tempo grande, os óvulos ficam tipo que envelhecidos'”.

Cerca de um mês depois do aborto, Juliana volta a engravidar, mas só tem conhecimento disto quando já estava sofrendo uma nova perda gestacional. O segundo aborto causou-lhe certo abalo emocional, "levei um baque", o qual tentou minimizar construindo a ideia de que esses embriões perdidos poderiam ter sido malformados. Na ocasião da perda, relata ter ligado para a "sua" médica para avisar-lhe acerca do ocorrido: "liguei pra minha médica mesmo e contei a ela, ela: 'É, Julianinha, tem alguma coisa estranha, vamos investigar... Aí comecei a investigar, não foi uma investigação muito a fundo, fiz alguns poucos exames, mais superficiais, e aí nada, não acusou nada". Na medida em que nenhum fator orgânico foi identificado como uma possível causa para a perda vivenciada, médica e paciente constroem a suposição de uma causa emocional, relacionada especialmente aos conflitos com o parceiro.

A terceira gestação despertou-lhe sentimentos ambíguos de "felicidade" e "medo". O sentimento de medo esteve relacionado às lembranças das perdas anteriores (passado) e à expectativa de que uma nova perda pudesse voltar a ocorrer (futuro): "eu já 'tava' com medo; como eu já tinha os dois abortamentos prévios, aí eu já 'tava' com medo, essa já foi uma gravidez totalmente, assim, apreensiva, 'né', eu fiquei totalmente apreensiva". 
Juliana relata que nessa gestação conseguiu, pela primeira vez, ouvir os batimentos cardíacos do bebê através do exame do ultrassom - o que lhe fez pensar que essa gravidez poderia ter êxito:

Quando eu vi os batimentos da criança, foi o único das três gravidezes, foi o único que eu ouvi os batimentos, ah, é uma sensação tão gostosa... tão gostosa, você ouvir lá, tá, tá, tá, os batimentos. Depois de você ter perdido dois, você vê um ali já bem grandinho e com os batimentos, aí foi que a gente (ela e a médica) achou que ia dar certo mesmo. Aí eu me enchi de esperança, já comprei roupa, fiz um bocado de coisa que não devia ter feito, de comprar, já começar o enxoval.

Porém, outra marca, ao mesmo tempo física e simbólica, daria fim às suas esperanças de sucesso gestacional. Afinal, na oitava semana de gestação, teve um pequeno sangramento, "esta é uma lembrança muito cruel... uma angústia profunda". Realizou em si mesma o exame de toque e percebeu que o sangramento era proveniente do seu útero. Entrou em contato com um amigo médico e ultrassonografista, que foi até sua casa, levando os equipamentos do ultrassom. Através desse exame, diagnosticou-se óbito fetal. Relata que entrou em "desespero" e imediatamente foi para Salvador, com um motorista e uma amiga auxiliar de enfermagem. Mas a "sua" médica confirmaria o diagnóstico, momentos depois, com a repetição do exame. Na medida em que se tratava de um aborto retido, precisou submeter-se ao procedimento chamado Aspiração Manual Intrauterina (AMIU), realizado em um hospital particular. A experiência da hospitalização consiste em uma lembrança dolorosa, não só pelo procedimento médico ao qual foi submetida, mas pelo fato de ter sido internada no setor da maternidade. Relata o contraste da sua experiência de perda gestacional com o nascimento de outros bebês, cujos quartos tinham nas portas elementos simbólicos que representavam o nascimento das crianças:

Essa foi a pior parte, a pior parte de todas desse abortamento, dessas perdas, foi esse internamento, a frustração de você estar ali já é muito grande, de você ter perdido já a terceira criança e eles te internam numa, na maternidade, eu fiquei internada na maternidade, todas as crianças nascendo e só a minha morrendo... 
Então imagina, você triste porque perdeu a criança, internada numa maternidade onde você ouve um bocado de choro de criança nascendo, sem comer, sem beber e sentindo dor e sangrando... a pior parte foi essa.

A experiência da terceira perda, deste modo, levou-lhe a um "desespero total". Afinal, enquanto médica sabia que se tratava de aborto de repetição, o que tornava evidente a incerteza em relação ao seu futuro reprodutivo: "o terceiro, que foi um desespero, que foi o pior de todos, porque aí realmente confirmou que era abortamento de repetição".

Nos dias que se seguiram a esta perda, Juliana relata ter sentido muita tristeza, sensação de "vazio", de "inutilidade" e "angústia": "a sensação é que eu nunca vou voltar a ter alegria... Eu estava fragilizada, dormia com remédios, me sentia uma morta-viva". A pergunta inevitável que persistia em seus pensamentos era: "por que comigo?". Em busca de uma resposta, que explicasse as experiências de perda no passado e minimizasse as incertezas no futuro, houve a procura por especialistas em aborto de repetição, dando início a uma vasta investigação. E, apesar dos obstáculos experienciados ao longo da sua trajetória, a expectativa de futuro continuou em direção à maternidade:

Eu espero engravidar [risos]...eu espero ser mãe, era tudo o que eu mais quero ainda [ênfase]. Assim, quando me vem a possibilidade de eu engravidar, eu lembro a dor, o desespero que eu passei nesse último aborto e isso eu não quero mais nunca na minha vida, então, vem o medo, vem o medo, o trauma que eu fiquei daquele Português [hospital], daquela maternidade, mas além, apesar disso tudo, além não, apesar desse medo, desse trauma que eu fiquei, eu ainda quero.

\section{As dinâmicas no âmbito do self: a tentativa de construir um sentido de continuidade}

No decorrer da trajetória reprodutiva de Juliana, a experiência de cada perda gestacional despertou-lhe diferentes afetos, que estiveram relacionados a distintas construções de significados pessoais. Tais significados 
foram construídos enquanto estratégias para produzir coesão em um self complexo, marcado pela experiência de sucessivas rupturas. (Abbey \& Falmagne, 2008) A experiência da primeira perda gestacional ganhou sentido, deste modo, a partir da perspectiva da medicina, do conhecimento que possui, enquanto ginecologista, sobre a ocorrência relativamente frequente de aborto espontâneo em uma primeira gestação. Assim, apesar de ter vivenciado uma ruptura daquilo que era esperado ocorrer, o significado de "normalidade" atribuído a esse evento minimizou o seu impacto emocional no âmbito do self - criando continuidade em meio à ruptura.

A ocorrência de uma segunda perda gestacional, porém, pareceu provocar um impacto emocional um pouco mais significativo, ampliando o nível de ambivalência experienciado. Afinal, nessa situação, dois eventos inesperados ocorreram simultaneamente: a notícia da gravidez a partir da sua interrupção espontânea. Mais uma vez, então, Juliana empenhou-se em construir sentido para o evento da perda utilizando os seus conhecimentos médicos. Nesse sentido, atribuiu ao aborto espontâneo a possibilidade de uma malformação fetal. Isto é, tentou codificar o evento disruptivo em um signo do tipo ponto (Valsiner, 2012), o que a conduziu a uma seleção restrita do campo da realidade. Porém, na medida em que essa consistia em apenas uma possibilidade da qual não era possível obter certeza - visto que Juliana não realizou, por exemplo, o exame de cariótipo do feto para determinar a suposta existência de malformação -, o signo construído não conseguiu reduzir significativamente o nível de ambivalência. Deste modo, outros signos precisaram ser coconstruídos com a sua médica ginecologista, como a possibilidade de uma causa emocional - em função dos conflitos existentes com o parceiro. Nesse segundo momento, então, a experiência do aborto espontâneo foi codificada sob a categoria de descrição do tipo campo ("causa emocional") que, de certo modo, conseguiu minimizar o nível de ambivalência - por se configurar em uma orientação para meta. Ou seja, a fim de evitar um novo aborto espontâneo, Juliana precisava minimizar os conflitos interpessoais com o parceiro. 
Porém, o terceiro aborto configurou-se em um episódio marcado por um elevado nível de ambivalência. A sua ocorrência abalou a frágil rede de sentidos construída anteriormente, provocando significativas repercussões para o senso do self. E isto ocorreu na medida em que a terceira perda gestacional enquadrou a situação dos abortos espontâneos no diagnóstico de aborto de repetição, exigindo a ressignificação das perdas anteriores. Os sentidos atribuídos anteriormente às perdas foram, deste modo, desconstruídos, perderam a consistência, e a incerteza frente ao futuro reprodutivo foi agudamente ampliada. Isto porque Juliana enquanto médica sabia que com esse diagnóstico a probabilidade de sofrer um novo aborto espontâneo era maior, bem como era mais difícil conseguir identificar as suas causas. Muitas indagações emergiram, refletindo essas incertezas: "será que eu vou ser capaz de ter filhos?", "e se eu não tiver filhos?”. As dúvidas foram reforçadas pela percepção do passar do tempo sentido no seu próprio corpo, por meio do limite biológico estabelecido para a sua capacidade reprodutiva. Ou seja, Juliana construiu a ideia de que não possuía muito tempo para conseguir ter o seu próprio filho, visto que já tinha 36 anos. As repercussões de todos esses significados no campo afetivo foram de tristeza ao olhar para o passado, e medo ao tentar vislumbrar o futuro.

Além disso, determinados entendimentos e/ou identidades tidas como certas - como a expectativa pessoal e social de tornar-se mãe e as crenças centrais de controle sobre a sua própria vida ("gosto de ter tudo sob controle") e de capacidade para conseguir aquilo que almeja ("tudo o que eu quis eu sempre consegui”) - foram seriamente ameaçados. Ou seja, Juliana relata ser alguém acostumada a planejar e controlar todos os aspectos da sua vida, e quando isto não foi possível - em decorrência dos abortos involuntários -, aspectos estruturantes da sua identidade foram colocados em risco. A experiência da não maternidade involuntária, deste modo, ameaçou alguns significados que atribuía a si mesma, ao mesmo tempo em que também colocou em risco o posicionamento simbólico que acreditava possuir na relação com outros significativos. 
A posição do Eu-mãe é altamente valorizada por Juliana, e muitas são as razões pessoais para isto. Primeiramente, tornar-se mãe consiste em um valor simbólico-cultural mediado e transmitido transgeracionalmente por sua família. E isto ocorreu não somente através das narrativas desses outros significativos, mas também através das experiências femininas de familiares com a maternidade e com a não maternidade: "fui criada com essa ideia: mulher tem que ter filhos. Sem filhos fica sozinha, sem motivação. Já a mãe vive em volta dos seus filhos". Juliana relata exemplos de tias que não tiveram filhos e atualmente vivem o que ela descreve como uma vida sem propósito, "sem motivação". Deste modo, havia uma expectativa pessoal e social para que se tornasse mãe - uma orientação afetiva ontogeneticamente internalizada.

[Esses] textos familiares são ideologias coletivo-culturais que orientam a escultura das realidades de interação social das pessoas em desenvolvimento ao longo de todo o seu curso de vida. Como tal, esses textos operam como signos promotores, fornecendo valor afetivo esmagador aos limites concretos que a família impõe. (Valsiner, 2012, p. 147)

Deste modo, os textos construídos pela família de Juliana circunscrevem alguns modos de agir: por um lado, excluem o não ter filhos do campo de possibilidades futuras - na medida em que o relacionam a um campo afetivo negativo, tal como a solidão - e, por outro lado, promovem o tornar-se mãe, ao atribuir a maternidade um valor afetivo altamente positivo. Assim, essas sugestões sociais configuram-se em um veículo para regular a vida pessoal de Juliana.

Partindo-se do pressuposto que toda construção de significado envolve signos de natureza dual - que consiste do núcleo A e seu contexto interdependente imediato Não-A (Cabell \& Valsiner, 2011), podemos analisar a relação estabelecida por Juliana entre maternidade $<>$ não maternidade. No decorrer da trajetória reprodutiva, orientada pela experiência afetiva de gravidez e abortos espontâneos - bem como influenciada por outros sociais significativos -, Juliana foi construindo novos signos, relacionados à contraparte "não maternidade", tais como sofrimento, 
dor, fracasso, inferioridade e solidão. Para fins de ilustração, a Figura 8 representa especificamente a emergência do signo solidão - enfatizado ao longo da narrativa construída por Juliana. Pode-se dizer que a relação dinâmica interna dos significados opostos em tensão "maternidade <> não maternidade", levou em direção a construção de uma síntese dialética. Assim, do campo do signo "não maternidade" houve a emergência de um novo signo, "solidão" (ver representação na Figura 8). Isto implicou “[...] na diferenciação dos opostos dentro do mesmo todo, sua relação de contradição e, como resultado, na superação da oposição prévia pela criação de uma nova totalidade”. (Cabell \& Valsiner, 2011, p. 94)

Figura 8 - Signo solidão como contraparte do signo hipergeneralizado maternidade

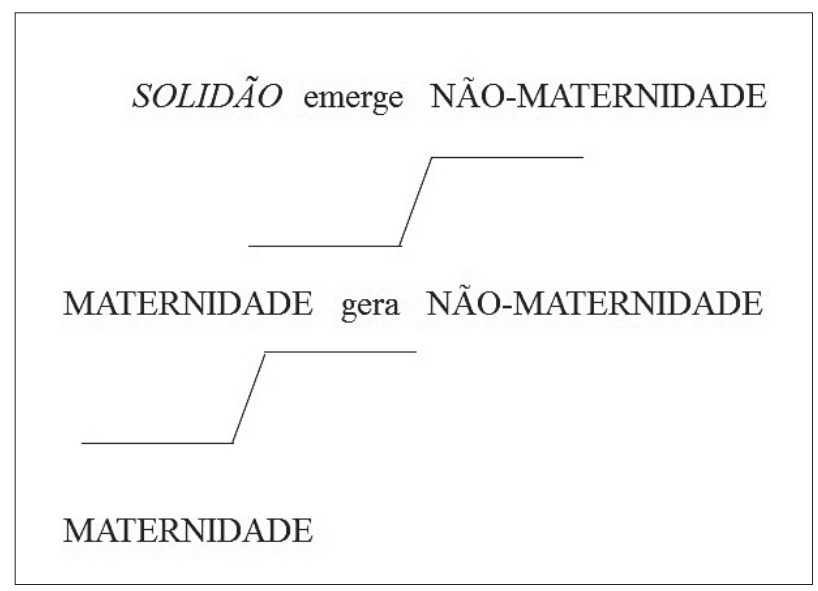

Fonte: elaboração da autora.

Por sua vez, esses signos construídos relacionados à contraparte "não maternidade" levaram, simultaneamente, à criação de novos signos para à outra contraparte, isto é, "maternidade", que passou a ser cada vez mais valorizada, idealizada e, por conseguinte, mais almejada por Juliana. Assim, por exemplo, ter um filho passou a significar o oposto da solidão, isto é, o "preenchimento do vazio" que, por sua vez, associou-se ao signo hipergeneralizado da "felicidade". 
Outra razão para seguir nessa direção consistiu no nascimento do filho do parceiro com uma outra mulher. Juliana relata que o parceiro desejava ter um filho, e ela desejava "dar um filho" para o parceiro. No entanto, o fato de uma outra mulher ter feito isto em seu lugar configurou-se em uma situação que Juliana não conseguiu suportar: "não aceito, não sei lidar", "ela teve um filho dele e eu não", "se eu não tiver filhos... e essa criança... eu prefiro a morte". Esse acontecimento despertou-lhe um senso de urgência para ter um filho e, deste modo, recuperar o valor simbólico não só perante o parceiro, mas perante a rede social próxima, como familiares e amigos: "eu queria provar para a sociedade que eu tive um filho com ele".

Assim, a experiência de perdas gestacionais espontâneas e o diagnóstico de aborto de repetição trouxeram implicações significativas para a sua identidade, modificando temporariamente a estrutura do self dialógico, através da orientação por signos (como representada na Figura 9). Isto porque Juliana passou a se sentir "diferente" das outras mulheres, consideradas "normais" - por não terem dificuldades para terem seus próprios filhos. Sentiu-se, deste modo, excluída do universo feminino - que tem a maternidade como uma das suas expressões mais significativas -, além de "incompleta" e "não realizada": "Você se acha diferente. Você não pode... você se acha a diferente, a excluída” (ênfase dada pela entrevistada). Juliana, então, luta para pertencer a uma determinada unidade social, classificada por ela como sendo das mulheres "normais", isto é, das mulheres férteis, que têm filhos. Conforme Valsiner (2012, p. 145), "[...] a noção de "participação" é um marcador semiótico de algum processo idealizado de pertencimento ou de não pertencimento". Assim, a participação nessa unidade social, tão almejada por Juliana, é uma ideação pessoal, apoiada por interações sociais concretas entre as pessoas: "Gostaria de ser igual a todo mundo". 
Figura 9 - Mudanças nas posições do Eu ao longo da trajetória reprodutiva
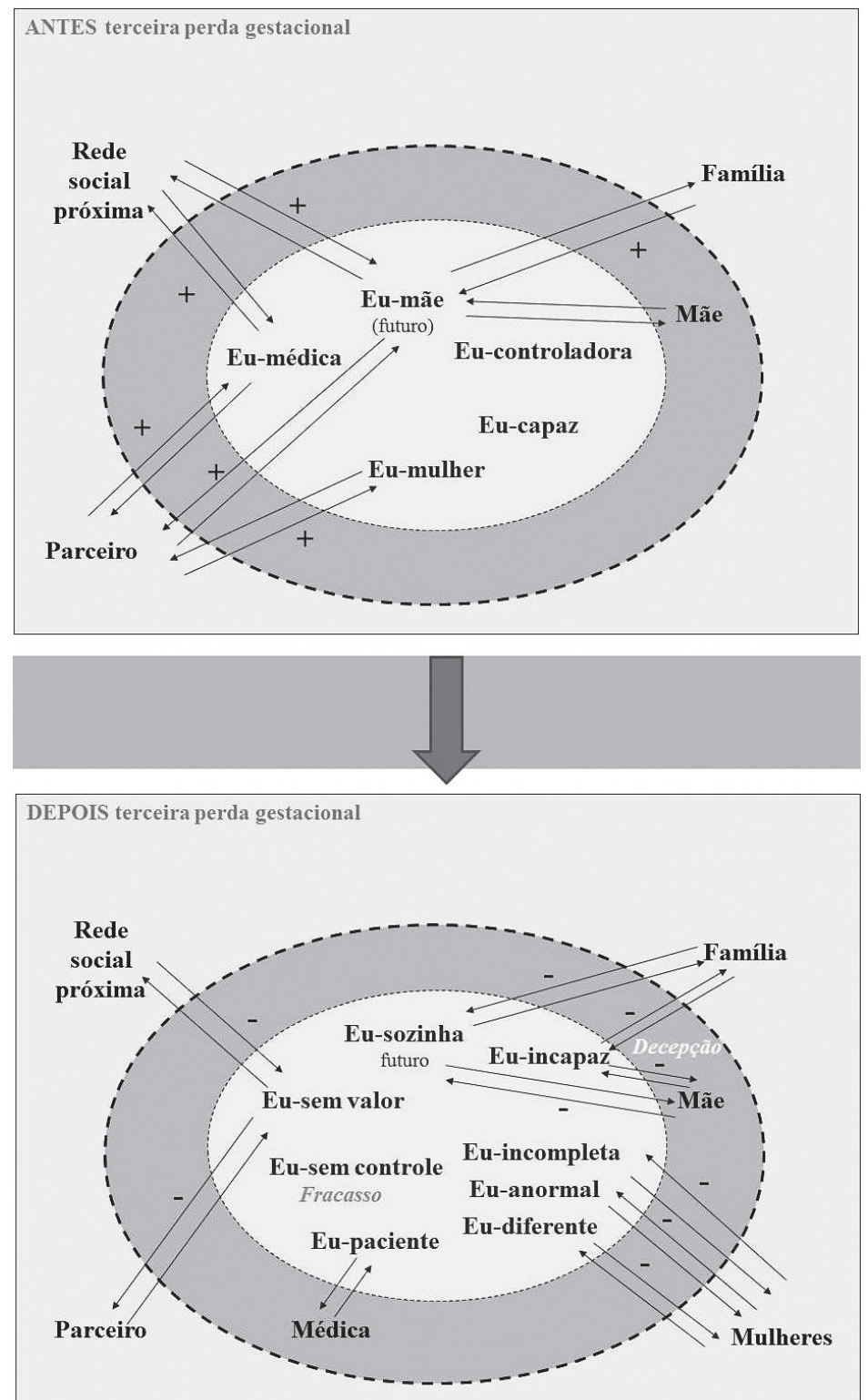

Fonte: elaboração da autora. 
A "incapacidade para ser mãe" é considerada, então, como uma "decepção" para consigo mesma e para os familiares. Além disso, essa experiência abalou a crença pessoal de que possui o controle sobre a sua própria vida, fazendo emergir uma sentimento de "fracasso" e de perda de controle. Deste modo, não só a posição Eu-mãe, futura e potencial, é ameaçada com a experiência dos abortos, mas também o Eu-mulher. Tais eventos disruptivos, assim, exigem processos de reposicionamento do self e solicitam novas aquisições, entendimentos e redefinições pessoais. (Zittoun, 2004) Nesse sentido, os significados pessoais acerca da maternidade são modificados no fluxo do tempo e adquirem valor, indo além do mero cumprimento do papel de gênero ou das expectativas sociais:

Eu passei a dar mais importância, porque... a gente só dá valor àquilo que a gente perde, a maioria das pessoas é assim, então,... eu achava que ser mãe era uma coisa normal, hoje eu já acho que ser mãe é a melhor coisa do mundo. Já que eu não posso ter, então... eu passei a valorizar muito mais, tanto que eu acho que se eu tiver, eu vou valorizar mais do que as outras pessoas, porque pra mim, ele veio, vai vir com mais dificuldade.

\section{O uso de recursos simbólicos e agência pessoal}

A fim de restabelecer um senso de continuidade no self, Juliana direcionou todos os seus esforços para conseguir obter êxito gestacional. Afinal, acreditava que tornar-se mãe lhe possibilitaria resgatar aspectos centrais da sua identidade - como ter controle sobre a sua própria vida -, satisfazer as demandas sociais implícitas nos textos familiares e recuperar o valor simbólico diante de outros sociais significativos. E para auxiliá-la nesse propósito contou com o apoio de familiares - especialmente sua mãe, que a incentivava a persistir na tentativa de ter um filho:

Quem participa mais de tudo é minha mãe, 'né'? Minha mãe 'tá' muito, muito desesperada, porque quando filho sofre, a mãe sofre junto, 'né'? Então ela fica tentando: "Não, não tem nada não, você vai engravidar e se não engravidar é porque Deus quis", essas coisas que todo mundo fala... mas ela acha que eu tenho que 
tentar ...Tratamento... ela acha o que eu falei aqui agora, que se eu engravidar é pra eu tentar de tudo. Ela acha que eu vou engravidar ainda...

A rede de apoio social consistiu, assim, em um recurso simbólico fundamental para a autorregulação e organização do self após a experiência dos eventos disruptivos:

'Affê' Maria, se não fosse isso, ninguém passa por isso sozinha, na verdade eu, o que mais me manteve assim, tentando, tentando levar pra frente, 'né', foi justamente o apoio de minha mãe, e dela também, 'né. Sozinha ninguém passa por isso não, tem que ter, tem que vir algum apoio.

Por sua vez, a busca por médicos especialistas consistiu em outro importante recurso utilizado por Juliana na tentativa de minimizar o elevado nível de ambivalência e aplacar as incertezas frente ao futuro reprodutivo. Relata que o que mais desejava era conseguir identificar algum fator responsável pelas perdas, passível de tratamento, para que então pudesse engravidar sem o medo avassalador de sofrer uma nova perda. A realização dos mais variados exames médicos, deste modo, apresentou a função de dar-lhe respostas, reduzindo a incerteza e as tensões que uma próxima gravidez poderia despertar. Deste modo, todos os exames solicitados pelo médico especialista foram realizados, mesmo aqueles que não eram cobertos por seu plano de saúde:

$\mathrm{Na}$ medida em que você investiga, você vai tentar achar uma causa pra poder tratar e aí ter o filho. Na minha cabeça assim, eu queria saber por que, primeiro pra você ter uma certeza, todo mundo que tem uma coisa, quer saber o porquê dessa coisa, então eu queria descobrir, se eu não posso ter filho, por que que eu não posso ter um filho, em primeiro lugar isso. Em segundo lugar, principalmente pra descobrir porque pra poder tratar, você não pode tratar sem descobrir o que é.

Porém, ao realizar os muitos exames solicitados pelo médico especialista, não obteve respostas definitivas, mas somente a identificação de alguns fatores que poderiam estar relacionados com as perdas experienciadas: "mas é tudo assim, uma possibilidade, a gente não tem certeza". Na busca por certezas, Juliana recorreu a outros especialistas e realizou ou- 
tros exames. Porém, a incerteza ressurgiu através das divergências entre os discursos dos especialistas sobre as causas e os possíveis tratamentos para o aborto de repetição. Novamente, o nível de ambivalência foi intensificado. Com o propósito de minimizá-lo, para então, planejar uma nova gravidez, Juliana recorreu à estratégia de bricolagem de significados, reunindo a miríade de possibilidades de tratamento sugerida pelos médicos especialistas, com o objetivo de cobrir todas as possíveis causas dos abortos espontâneos e, deste modo, evitar uma nova perda. Evidencia-se, então, o esforço de Juliana em construir alguma "certeza" para o futuro reprodutivo, reduzindo a ambivalência no momento presente:

Vou continuar investigando. Agora, se eu engravidar de novo, ele (médico especialista A) não quer que eu engravide não, de novo, nem Dr. M. (médico especialista B), nenhum dos dois me liberou ainda, mas eu acho que se eu engravidar de novo eu vou usar a heparina, aspirina, tudo aí pra tentar...se ninguém sabe? Um médico diz uma coisa, o outro médico diz outra coisa, aí, não sei...

Além disso, na medida em que uma das possíveis causas dos abortos podia ser de ordem emocional, em decorrência dos conflitos com o parceiro, Juliana deu início a um processo psicoterapêutico. Deste modo, através das suas ações e pensamentos, Juliana buscou retomar o controle sobre a sua própria vida, atuando como um agente ativo, que se apropria, resiste, transforma e modula os diferentes discursos sociais e recursos simbólicos disponíveis (Abbey \& Falmagne, 2008), persistindo na direção da maternidade.

Juliana voltou a engravidar novamente, alguns meses depois da realização da entrevista. Apesar do planejamento prévio em submeter-se a todos os tratamentos médicos possíveis - a fim de evitar a repetição de um aborto espontâneo -, a gravidez só foi percebida quando já havia passado o período considerado crítico pela medicina para a ocorrência de abortos espontâneos. Para esse fato, Juliana construiu o significado de "providência divina". Ou seja, acredita que "Deus" concedeu-lhe o não saber da gravidez, uma condição na qual não houve a tensão entre a "certeza" e a "incerteza”, logo, não houve a emergência da ambivalência. 
Durante a gravidez, tentou circunscrever o campo afetivo relacionado ao processo do tornar-se mãe: "você não tem noção do que é felicidade". Assim, em vez de tentar algum tratamento médico, deu apenas continuidade ao acompanhamento psicológico que já vinha realizando desde a última perda gestacional. E a quarta gestação resultou no nascimento de um bebê a termo: "A vida toda desejei isso. 37 anos esperando isso, meu sonho realizado... Hoje eu sinto que consegui”.

A Figura 10 ilustra os principais aspectos analisados da trajetória reprodutiva de Juliana, com ênfase para as estratégias semióticas para a construção de continuidade e manutenção da posição Eu-mãe após a terceira perda gestacional. 


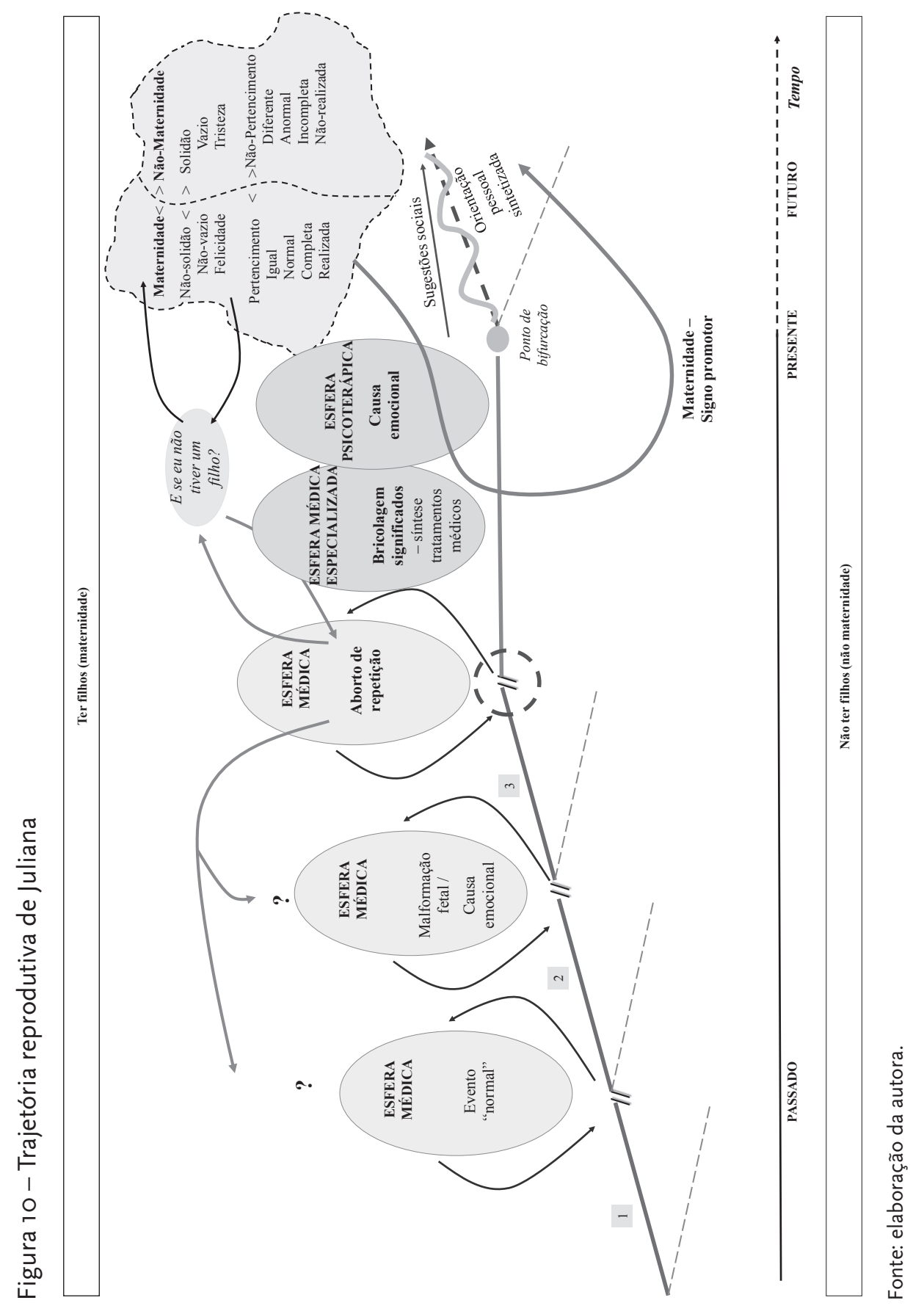

